\title{
Surgical Thrombectomy for Thrombosed Dialysis Grafts: Comparison of Adjunctive Treatments
}

\author{
Yun-Hen Liu $\cdot$ Yen-Ni Hung $\cdot$ Hung-Chang Hsieh $\cdot$ \\ Po-Jen Ko
}

Published online: 29 January 2008

(c) Société Internationale de Chirurgie 2008

\section{Erratum to: World J Surg}

DOI: 10.1007/s00268-007-9202-4

In the above-mentioned article, published online on December 8, 2007, three of the four authors' names were inadvertently omitted. The correct list of authors is shown above. Per PubMed and SpringerLink regulations, the online and print versions of all articles must exactly duplicate each other. Therefore, the authors' names are omitted from the print article, which appears in the February issue (volume 32/number 2, pp 241-245).

The online version of the original article can be found under doi: 10.1007/s00268-007-9202-4.

Y.-H. Liu · H.-C. Hsieh · P.-J. Ko (ه)

Division of Thoracic and Cardiovascular Surgery, Chang Gung

Memorial Hospital, Chang Gung University, Taoyuan, Taiwan

e-mail: pjko@adm.cgmh.org.tw

Y.-N. Hung

Institution of Public Health, National Yang-Ming University,

Taipei, Taiwan 